\title{
UM EXPERIMENTO COM PROPOSTAS MÚLTIPLAS PARA UM LABORATÓRIO DE QUÍMICA GERAL
}

\author{
Déborah de Alencar Simoni, João Carlos de Andrade, José Fernando Gregório Faigle e José de Alencar Simoni* \\ Instituto de Química, Universidade Estadual de Campinas, CP 6154, 13083-970 Campinas - SP
}

Recebido em 21/10/01; aceito em 8/3/02

\begin{abstract}
A MULTI PURPOSE EXPERIMENT FOR GENERAL CHEMISTRY LABORATORY. This article suggests a sequence of experiments on the preparation, analysis and some photochemical aspects of potassium tris (oxalato) ferrate(III) trihydrate. The sequence of experiments could be carried out in four or five 4-hour laboratory periods. The new part of this article is related to the kinetics studies involving the ambient illumination as well as the use of the cellophane paper of different colors as light filters. The aspects such as quantum yield, light absorption and photochemical reactions are explored in order to illustrate the relationships between the exposure time, light intensity and wavelength range on the photochemical reactions.
\end{abstract}

Keywords: photochemical reactions; kinetic; general chemistry.

\section{INTRODUÇÃO}

As notáveis alterações que os guias de laboratórios e as revistas especializadas no ensino de química vêm sofrendo nos últimos tempos são uma prova contundente de que é preciso, com urgência, acompanhar estas alterações. Como professores, devemos acreditar que novas propostas de ensino, após serem bem analisadas e, quando reforçadas por resultados positivos, devem ser aplicadas. Neste sentido, propostas de novas metodologias de ensino de Química experimental no terceiro grau, onde aparecem indicações como: "faça você próprio", "descoberta", "cooperativismo" e "construtivismo", em detrimento ao tradicional "livro de receitas", são bastante atuais e promissoras $^{1-5}$.

É claro que não se pode romper definitiva e totalmente com o uso de apostilas e livros de receitas ("cook book"), mas vê-se que o seu uso tem diminuído bastante no ensino universitário. Não há uma técnica pronta para se sair do tradicional "livro de receitas", para uma proposta mais criativa e que dê melhores resultados no ensino experimental de química. Embora alguns aspectos deste ensino tradicional possam ser mantidos, mesmo porque, é difícil adaptar-se, por exemplo, o ensino de técnicas experimentais a um formato completamente novo e diferente do convencional, sempre é possível criar-se situações novas e facilitadoras da aprendizagem, pela simples valorização da motivação do aluno, a quem se deve permitir escolher e desenvolver um "caminho próprio" na experimentação.

Este artigo traz uma sequiência de experimentos que podem ser utilizados em uma ou mais disciplinas experimentais de Química, ou aplicados em diferentes graus de dificuldade, dependendo do nível dos alunos (fase curricular em que se encontram dentro do curso).

A idéia principal dos experimentos propostos é possibilitar o aprendizado de técnicas simples de síntese e purificação de substâncias, como aquecimentos, resfriamentos, pesagens, dissoluções, reações químicas, filtrações, recristalizações, preparo de soluções, etc, e também o uso de técnicas de análise, como titulação, espectrofotometria, cinética etc... Trata-se, pois, de um projeto completo a ser aplicado durante várias atividades experimentais em seqüência.

A principal substância utilizada nestes experimentos é o sal do actinômetro de Parker $^{6}, \mathrm{~K}_{3}\left[\mathrm{Fe}\left(\mathrm{C}_{2} \mathrm{O}_{4}\right)_{3}\right] \cdot 3 \mathrm{H}_{2} \mathrm{O}$ (tris(oxalato) ferrato(III)

\footnotetext{
*e-mail: caja@iqm.unicamp.br
}

de potássio, tri-hidratado), um sólido de cor verde claro, que pode ser preparado rapidamente, como mostra o experimento I proposto. Além desta síntese, o aluno terá oportunidade de fazer uma análise elementar do sólido preparado e determinar sua fórmula molecular (experimentos II e III).

Os experimentos I, II e III já se encontram descritos na literatu$\mathrm{ra}^{7-12}$, mas, devido às dificuldades de acesso à bibliografia, encontradas por vários de nossos colegas Professores, tomamos a liberdade de apresentá-los novamente aqui, como forma de facilitar o uso dos mesmos. No entanto, seus roteiros são apresentados aqui de forma resumida, como sugerimos que devam ser oferecidos aos alunos. $\mathrm{O}$ experimento IV, que corresponde à parte inédita deste trabalho, trata de um estudo cinético envolvendo uma reação de oxidação e redução induzida por luz, um assunto muito importante, porém pouco explorado nos cursos de Química.

Os roteiros experimentais aqui propostos deram bons resultados quando aplicados, e estão escritos de maneira não convencional, já obedecendo aos princípios inicialmente comentados nesta introdução. O colega Professor pode verificar que várias informações não são dadas aos alunos, como forma de estimulá-los a pesquisar e compartilhar tarefas e informações.

Como regra geral, algumas informações ou questões apresentadas em negrito nos roteiros sugeridos são tópicos que os alunos têm que pesquisar e trazer para uma discussão prévia sobre o experimento a ser realizado. Entretanto, levando-se em conta o material bibliográfico disponível na sua Universidade, o Professor deve decidir quais são as informações que os alunos podem buscar e devem encontrar na biblioteca. Evitando, ao máximo, tornar punitivas as tarefas preliminares que os alunos devem realizar e, ao mesmo tempo, tentando garantir que os alunos se preparem adequadamente para as atividades laboratoriais e discussões prévias sobre o experimento, as questões em negrito e um breve resumo do procedimento experimental devem ser entregues, por escrito, por cada aluno antes do inicio da aula. Este material é parte da avaliação (no nosso caso, 30\% da nota de relatório, nota esta que corresponde a $30 \%$ da avaliação da disciplina).

Cada experimento é precedido de uma discussão realizada na primeira hora de laboratório com a participação de todos os alunos, os quais são voluntários e onde o Professor é apenas um "âncora". Geralmente, cada aluno expositor participa por um período limitado de tempo. A troca geralmente é realizada quando o aluno está se 
saindo muito bem e já deu uma contribuição significativa para a aula, ou quando ele faz alguma confusão (intervenção do Professor) e outro aluno se propõe a resolver o problema. Nesta situação, automaticamente o novo aluno é convidado a continuar a exposição. Para favorecer a maior participação dos alunos, permite-se que o primeiro expositor comece por onde ele se julga mais seguro. Ao final desta discussão o Professor faz um resumo dos aspectos mais relevantes da atividade do dia.

Os experimentos aqui descritos poderão ser realizados em cinco aulas experimentais de quatro horas cada: na primeira aula o composto pode ser sintetizado e purificado por recristalização, e a sua quantidade de água determinada gravimetricamente.

Na segunda aula poderá ser feita a determinação do teor de oxalato presente no complexo e na terceira aula, a quantidade estequiométrica de ferro, finalizando com a determinação da fórmula molecular do composto sintetizado.

Na quarta e quinta aulas poderá ser estudada a cinética da reação de oxidação e redução que ocorre entre o íon Fe(III) e o íon oxalato em meio ácido, reação esta que é a base da determinação actinométrica.

Os roteiros para os estudos cinéticos não se esgotam com as sugestões aqui apresentadas e o colega Professor descobrirá facilmente que diversas outras possibilidades se apresentarão durante a aplicação dos roteiros propostos neste artigo.

Finalmente, num projeto como este, deve-se permitir que o aluno tenha o seu próprio ritmo, não se esquecendo que se está falando em alunos ingressantes. Cada atividade pode ser facilmente cumprida no período de quatro horas, mesmo para os alunos com maiores dificuldades. A síntese do composto é o único ponto em que um resultado negativo poderia comprometer a seqüência experimental. No entanto, esta hipótese é praticamente nula para este caso específico, em vista da facilidade de obtenção do composto.

\section{PROCEDIMENTOS EXPERIMENTAIS}

\section{Experimento I}

\section{Preparação do complexo e determinação de água de cristalização}

\section{Preparação}

Adicione, à quente $\left( \pm 60^{\circ} \mathrm{C}\right)$, cerca de $8,0 \mathrm{~mL}$ de uma solução $0,4 \mathrm{~g} / \mathrm{mL}$ de cloreto de ferro(III) a uma solução, também aquecida, contendo $12 \mathrm{~g}$ de oxalato de potássio em $20 \mathrm{~mL}$ de água. Deixe a mistura esfriar até a temperatura ambiente e depois, com o auxílio de um banho de gelo, resfrie-a até $0^{\circ} \mathrm{C}$. Mantenha a temperatura até a cristalização do sal se completar. Decante a água mãe para recristalizar o produto.

Redissolva o sólido em $20 \mathrm{~mL}$ de água quente e resfrie a solução resultante a $0{ }^{\circ} \mathrm{C}$ para precipitar o produto. Filtre o sólido em funil Büchner e lave-o com uma pequena quantidade de água. [Quente ou fria? Por que?]

Lave o sólido, ainda no funil, com duas porções de metanol (cuidado! Substância tóxica) gelado, para remover o excesso de água. Triture o produto até obter um sólido de granulação fina. Deixe-o secar em uma capela, sob ventilação, por cerca de $10 \mathrm{~min}$, ao abrigo da luz.

\section{Determinação da quantidade de água}

Lave adequadamente (use detergente e água) dois vidros relógio, coloque-os na estufa por cerca de $30 \mathrm{~min}$, retire-os sem tocar diretamente com os dedos e deixe-os esfriarem até à temperatura ambiente. Pese-os e adicione a cada um deles, aproximadamente, metade do sólido preparado anteriormente e pese novamente. [É preciso determinar estas massas com precisão? Por que?]
Coloque os dois vidros relógio (com o sólido) novamente na estufa por cerca de $90 \mathrm{~min}$. Após este tempo, retire-os da estufa e deixe-os esfriarem no dessecador, até a temperatura ambiente. Pese os vidros relógio com as amostras e determine a nova massa de sólido após a eliminação da água de cristalização. [É preciso determinar esta massa com precisão? Por que?]

Guarde o sólido obtido em um frasco de vidro, envolto por papel alumínio, para evitar a exposição à luz.

\section{Resultados, cálculos e discussão}

Você deve apresentar nos seus resultados a massa de sólido obtido e calcular a porcentagem de água neste sólido. Como você ainda não conhece a fórmula da substância preparada, estes são os resultados possíveis até o momento. Nos experimentos subseqüentes você poderá calcular outras quantidades, inclusive determinar a fórmula empírica do sólido. Apresente no relatório as respostas para todas as questões levantadas, desenhe cada um dos utensílios de laboratório usados, e descreva resumidamente sua utilidade e forma correta de manuseio.

Compare os resultados com os de seus colegas (em relação ao rendimento e ao tipo de sólido obtido), justifique e comente as semelhanças e as diferenças.

\section{Experimento II}

\section{Determinação de quantitativa de oxalato}

\section{Procedimento}

O oxalato presente neste sólido pode ser determinado por titulação com solução de permanganato de potássio em meio ácido. Verifique a literatura a respeito ${ }^{13,14}$. Verifique como é a preparação das soluções e como se procede na titulação utilizando solução de permanganato de potássio. Divida as tarefas de preparação e padronização desta e de outras soluções necessárias, e dimensione com os outros grupos de sua bancada as quantidades de soluções que devem ser preparadas. Mostre ao professor as decisões da bancada.

A determinação da quantidade de oxalato existente no sólido deve ser feita com as luzes do laboratório apagadas, para evitar a exposição à luz. Compartilhe os dados com todos os outros grupos do laboratório. Coloque no quadro negro os seus resultados e apresente o conjunto de todos os resultados em seu relatório.

\section{Discussão}

Discuta sobre a precisão das determinações da porcentagem de oxalato, calculando para tal, os desvios e incertezas ${ }^{15-17}$. Expresse seus resultados utilizando a linguagem científica adequada e estabeleça razões para os resultados obtidos. Por enquanto, ainda não se pode estabelecer a fórmula do sólido.

\section{Experimento III}

\section{Determinação quantitativa de ferro}

\section{Procedimento}

Você está preste a determinar a fórmula do sólido que foi preparado. O teor de água (experimento I ) e o teor de oxalato ( experimento II) já foram obtidos. Seu sólido possui ainda os elementos ferro e potássio em sua molécula. Se você determinar um deles, o outro poderá ser obtido por cálculos. Mais à frente em seu curso você poderá fazer experimentos onde o potássio poderá ser determinado por fotometria de chama (emissão atômica). Por agora, no entanto, a determinação de ferro é mais simples e apropriada.

Geralmente o ferro é determinado quantitativamente na forma 
do seu respectivo íon ferro(III). Todo ferro da amostra é oxidado completamente a ferro(III), precipitado na forma de hidróxido e determinado gravimetricamente na forma de óxido. Esta determinação é bastante exata, mas agora você irá determinar quantitativamente o ferro por uma outra técnica mais simples, reduzindo os íons Fe(III) para o seu estado de oxidação (II) e determinando-o espectrofotometricamente ${ }^{18,19}$.

Inicialmente, em um balão de $100 \mathrm{~mL}$, dissolva cerca de $20 \mathrm{mg}$ [É necessário conhecer com precisão esta massa?] do seu sólido em solução de ácido sulfúrico $\left(0,05 \mathrm{~mol} \mathrm{dm}^{-3}\right)$. Deixe a solução obtida exposta à luz solar por cerca de $2 \mathrm{~h}$. Haverá uma reação de oxidação e redução entre os íons $\mathrm{Fe}(\mathrm{III})$ e $\mathrm{C}_{2} \mathrm{O}_{4}{ }^{2-}$, induzida pela luz, que se denomina reação fotoquímica.

Após duas horas de exposição ao sol, tome um volume conhecido da mesma, e proceda a sua reação com 1,10-fenantrolina, como descrito a seguir para a curva analítica e faça as medidas de absorbância. Veja que você não tem definido o volume que deve ser utilizado desta solução. Escolha um volume qualquer, proceda a revelação da cor e decida, se, e como ele deve ser modificado na próxima determinação. Faça esta determinação em triplicata. Caso o tempo esteja nublado ou o experimento esteja sendo realizado no período noturno, faça a redução do $\mathrm{Fe}$ (III) para $\mathrm{Fe}$ (II) com solução de hidroxilamina ${ }^{7,18}$.

Enquanto espera a reação se completar, prepare uma bateria de soluções de sulfato ferroso amoniacal, para construir a curva analítica, conforme procedimento a seguir:

\section{Curva analítica}

A uma série de 8 balões volumétricos de $100 \mathrm{~mL}$, adicione, separadamente a cada um deles os volumes: 10, 15, 20, 25, 30, 35 e 40 $\mathrm{mL}$ de uma solução padrão de $\mathrm{Fe}(\mathrm{II})\left(10 \mathrm{mg} \mathrm{dm}^{-3}\right)$, recém preparada em $\mathrm{H}_{2} \mathrm{SO}_{4} 0,05 \mathrm{~mol} \mathrm{dm}^{-3}$ (esta solução será fornecida pelo Professor e pode ter sido preparada pela diluição de uma solução $0,1 \mathrm{~mol} \mathrm{dm}^{-3} \mathrm{de}$ $\mathrm{FeSO}_{4}$ em meio sulfúrico $0,1 \mathrm{~mol} \mathrm{dm}^{-3}$, recém preparada e padronizada). [Estes volumes devem ser conhecidos com precisão?] Em um outro balão de $100 \mathrm{~mL}$, coloque $50 \mathrm{~mL}$ de água destilada, que será o "branco".

Adicione a cada um destes 8 frascos, $10 \mathrm{~mL}$ de uma solução tampão de concentração total $2 \mathrm{~mol} \mathrm{dm}^{-3}$ de ácido acético / acetato de sódio ( $\mathrm{pH}=4,5)$ e depois $5,0 \mathrm{~mL}$ da solução reagente de 1,10 fenantrolina $\left(1 \% \mathrm{~m} / \mathrm{v}\right.$ em $\left.\mathrm{H}_{2} \mathrm{SO}_{4} 0,1 \mathrm{~mol} \mathrm{dm}^{-3}\right)$. Deixe as soluções em repouso por $60 \mathrm{~min}$ ao abrigo da luz. Depois dilua cada uma delas até à marca dos $100 \mathrm{~mL}^{18}$. Calcule as concentrações de $\mathbf{F e}$ (II) de cada solução e construa uma tabela onde serão inseridos os resultados de absorbância a serem medidos na seqüência.

Faça medidas de absorbância para todas as soluções no comprimento de onda de $510 \mathrm{~nm}$. Para isto, consulte inicialmente o manual de instruções do instrumento, discuta com seus colegas e relate ao professor como pretende fazer as medidas. Só então comece a fazêlas.

\section{Resultados, cálculos e discussão}

Comente sobre a exatidão e precisão do método utilizado, as dificuldades e os cuidados experimentais. Pesquise, em revistas ou livros, como seus dados podem ser convenientemente tratados e apresentados em forma de tabelas e gráficos. Determine a quantidade de ferro no sólido.

Como agora você já determinou as porcentagens em massa de água, oxalato e $\mathrm{Fe}(\mathrm{III})$, você já pode calcular, por diferença, a porcentagem de potássio no sólido preparado. Comente sobre a precisão da determinação do potássio, levando em conta a propagação de incertezas. Por fim, por cálculos determine a fórmula do sólido preparado. Com base nesta fórmula e na estequiometria da equação quí- mica que agora você conhece, calcule o rendimento da reação de síntese deste sólido (complexo). Indique e justifique qual foi o reagente limitante na síntese.

\section{Experimento IV}

Estudo cinético e actinometria usando o sal do actinômetro de Parker $^{6}-\mathrm{K}_{3}\left[\mathrm{Fe}\left(\mathrm{C}_{2} \mathrm{O}_{4}^{2-}\right)_{3}\right] \cdot 3 \mathrm{H}_{2} \mathrm{O}$

\section{Introdução}

Da região do ultravioleta até aproximadamente $510 \mathrm{~nm}$ (no visível) o rendimento quântico (procure saber o significado deste termo, de uma forma bem simplificada) desta reação é próximo de 1; o que torna este sal apropriado a experimentos actinométricos nessa região do espectro eletromagnético.

A determinação da quantidade de fótons em um feixe qualquer de luz, geralmente é feita por meios eletrônicos, onde um determinado sensor ao ter um feixe de luz incidindo sobre si dá uma resposta, a qual pode servir de base na determinação da quantidade de fótons no feixe (Actinometria).

Em trabalhos mais rigorosos, onde a quantidade de fótons emitidos por uma fonte precisa ser conhecida com exatidão, em algum momento é necessário um método padrão para calibrar o instrumento $^{20}$. A substância que você preparou é, normalmente, muito utilizada como padrão em actinometria. Às vezes ela é designada como a substância do actinômetro de Parker $^{6}$, e a equação química da reação de oxidação e redução que ela sofre é:

$$
\mathrm{Fe}^{3+}{ }_{(\mathrm{aq})}+1 / 2 \mathrm{C}_{2} \mathrm{O}_{4}^{2-}(\mathrm{aq})=\mathrm{Fe}_{(\mathrm{aq})}^{2+}+\mathrm{CO}_{2(\mathrm{~g})}
$$

\section{Estudo da cinética fotoquímica (aspectos qualitativos)}

Dissolva entre 100 e $200 \mathrm{mg}$ do sólido obtido em $100 \mathrm{~mL}$ de solução $0,05 \mathrm{~mol} \mathrm{dm}^{-3} \mathrm{de}_{2} \mathrm{SO}_{4}$. Utilize um balão envolto por papel alumínio. [Por que?]

Tome cinco tubos de ensaio semelhantes. Corte tiras de papel celofane nas cores verde, amarelo, vermelho e azul, suficiente para envolver os tubos de ensaio, dando três voltas completas. Prenda os papéis nas partes inferior e superior dos tubos utilizando pequenas tiras de fita adesiva transparente. Agora envolva todos os tubos, inclusive aquele sem o papel celofane, em papel alumínio.

Evitando ao máximo a luz ambiente, adicione, a cada tubo, $5 \mathrm{~mL}$ da solução preparada [o volume precisa ser conhecido com precisão?]. Após preencher todos os tubos, retire o papel alumínio que os cobre e comece a cronometrar o tempo, deixando os mesmos expostos à luz ambiente (dentro do laboratório) de maneira uniforme, durante $90 \mathrm{~min}$.

Enquanto espera decorrer os 90 min de exposição, faça o espectro de absorção de luz para os diversos papéis celofane. Utilize água como branco no espectrofotômetro e meça as absorbâncias em intervalos de $10 \mathrm{~nm}$, na faixa entre 400 e $700 \mathrm{~nm}$. Para tal, corte uma tira que encaixe perfeitamente na parte interior de uma das paredes da cubeta. Faça isto, apenas, para uma das cores. Combine com outros três grupos de colegas, para que cada um repita o procedimento para uma outra cor e depois compartilhem os resultados.

Decorridos os 90 min, envolva cada um dos tubos novamente com o papel alumínio, adicione $1 \mathrm{~mL}$ de solução tampão $2 \mathrm{~mol} \mathrm{dm}^{-3}$ ácido acético/acetato $(\mathrm{pH}=4,5)$ e $1,0 \mathrm{~mL}$ de solução de 1,10 fenantrolina $(1 \% \mathrm{~m} / \mathrm{v})$. Agite bem os tubos e deixe-os ao abrigo da luz por $60 \mathrm{~min}$.

Decorrido este tempo, retire o papel alumínio de cada tubo e meça a absorbância de cada solução, em $510 \mathrm{~nm}$. Retire o papel de cada tubo individualmente e evite, ao máximo, a exposição da solução à luz. Retire a proteção de alumínio de cada solução somente 
no momento imediatamente anterior a cada medida. Faça na sequiência: vermelho, verde, amarelo, azul e sem papel. Como você não tem volumes suficientes de cada solução para lavar a cela, lave bem com água destilada e depois com um pequeno volume de solução a ser medida.

Não jogue fora as soluções. Compare suas cores, mas evite sempre que as mesmas sejam expostas à luz antes destas comparações. Após ter realizado as medidas e as comparações, deixe estas soluções expostas à luz natural e observe o que ocorre com as mesmas, no decorrer do tempo. Observe-as ininterruptamente por cerca de $10 \mathrm{~min}$.

\section{Resultados e discussão}

Pelos valores de absorbância, determine a concentração Fe(II) em cada tubo. Para isso, utilize os dados da curva analítica do experimento III. Não se esqueça de que você efetuou diluições das soluções originalmente expostas à luz. É para as soluções originais que você deve determinar a concentração de $\mathrm{Fe}$ (II) formado.

Construa uma figura contendo os espectros de absorção dos diferentes papéis celofane. Discuta a forma destas curvas com as cores que você vê através destes papéis. Veja se é possível estabelecer uma correlação entre estas curvas, seus aspectos quantitativos e qualitativos e a extensão da reação em cada caso.

Pense sobre combinações de dois papéis de cores diferentes envolvendo um mesmo tubo. [Quais seriam os resultados? Seria interessante verificar experimentalmente se sua resposta está certa? Como seria o procedimento experimental?]

\section{Estudo da cinética fotoquímica (aspectos quantitativos)}

Novamente dissolva entre 100 e $200 \mathrm{mg}$ do sólido obtido em $100 \mathrm{~mL}$ de uma solução $0,05 \mathrm{~mol} \mathrm{dm}^{-3} \mathrm{de}_{2} \mathrm{SO}_{4}$. Utilize um balão envolto por papel alumínio. [Por que?]

Tome seis tubos de ensaio, também envoltos em papel alumínio, adicione $5 \mathrm{~mL}$ da solução anteriormente preparada. [O volume precisa ser conhecido com precisão?] Após preencher todos os tubos, retire o papel alumínio que os cobre e comece a cronometrar o tempo, deixando os mesmos expostos à luz ambiente (dentro do laboratório), de maneira uniforme. A intervalos de tempo bem conhecidos, entre 5 e $40 \mathrm{~min}$, envolva cada um dos tubos novamente com o papel alumínio, anotando o intervalo de tempo que cada um esteve exposto à luz.

Ao final do experimento, cada tubo foi exposto à luz em diferentes intervalos de tempo. Se a presença de luz induz a reação fotoquímica, ao final do experimento cada tubo terá uma quantidade diferente de produtos formados em solução.

De forma semelhante ao estudo qualitativo, evitando ao máximo a exposição à luz, adicione $1 \mathrm{~mL}$ de solução tampão $2 \mathrm{~mol} \mathrm{dm}^{-3}$ ácido acético/acetato $(\mathrm{pH}=4,5)$ e $1,0 \mathrm{~mL}$ de solução de 1,10 fenantrolina $(1 \% \mathrm{~m} / \mathrm{v})$. Agite bem as soluções e deixe-as ao abrigo da luz por $60 \mathrm{~min}$.

Se as concentrações das soluções forem determinadas por comparação de cores contra uma bateria de soluções, utilize tubos de ensaio de mesmo diâmetro e espessura de parede. O mesmo é válido para medidas comparativas usando-se um único padrão de concentração, como é realizado na determinação da constante formação do $[\mathrm{FeSCN}]^{2+21}$. Caso a opção seja o uso de um espectrofotômetro, faça as medidas de absorbância para todas as soluções no comprimento de onda de $510 \mathrm{~nm}$. Neste caso, as concentrações de Fe(II) são obtidas pela curva analítica do procedimento do experimento III.

\section{Resultados, cálculos e discussão}

Determine a concentração ferro(II) em cada tubo em função do tempo. Não se esqueça de que você efetuou diluições das soluções originalmente expostas à luz. É para as soluções originais que você deve determinar a concentração de Fe(II).

Apresente seus dados em forma de tabela. Construa curvas da concentração de $\mathrm{Fe}$ (II) em função do tempo, do logaritmo neperiano (ln) da concentração de $\mathrm{Fe}$ (II) em função do tempo e do inverso da concentração de $\mathrm{Fe}$ (II) em função do tempo. Compare as diversas curvas e correlacione-as aos conceitos teóricos.

Compare seus resultados com os de seus colegas. Veja se eles são diferentes ou iguais. Tente encontrar justificativas para isto. Observe detalhes como a concentração utilizada, o tipo de tubo, a posição das luzes no laboratório, etc.

\section{CONSIDERAÇÕES FINAIS}

Após a realização destes experimentos, os quais foram aplicados em dois semestres consecutivos numa disciplina experimental introdutória de química, as avaliações que os alunos fizeram ao fim do semestre, obrigatórias em todas as disciplinas de graduação da Unicamp, mostraram que o uso de experimentos em sequiência vai ao encontro de seus anseios. Isto foi verificado no item deste questionário de avaliação, onde os estudantes fazem as suas manifestações espontâneas. Aspectos relevantes como o compartilhamento de dados e a resolução de tarefas coletivas, bem como a discussão em grupo sobre aspectos do roteiro experimental e a introdução da radiação como elemento necessário à ocorrência de reação química, destacaram-se entre tantos outros.

Os experimentos II e III podem ser mais convenientemente aplicados em disciplinas de Química Analítica Quantitativa. Não precisam ser, necessariamente, introduzidos em Química Geral, mas se o forem, o Professor deve atentar para o pouco treinamento dos alunos e também para as suas possíveis dificuldades.

O Professor não deve atribuir um valor alto aos resultados quantitativos na avaliação do relatório, em se tratando de Química Geral, já que muitos outros aspectos químicos importantes estão em evidência neste projeto. Entretanto, como se verifica pelos roteiros sugeridos, na apresentação dos resultados deve-se dar relevância a este aspecto.

No caso específico da determinação de ferro, se o laboratório não possui espectrofotômetros, o Professor pode optar por usar uma bateria de soluções como curva analítica e determinar concentrações por comparação visual de intensidades de cor. Os resultados não são tão bons do ponto de vista quantitativo, mas podem, inclusive, servir para se introduzir os conceitos de espectrofotometria ${ }^{21}$.

A determinação quantitativa de Fe(II) também pode ser feita por adição de ferricianeto ao invés da 1,10-fenantrolina. A absortividade do complexo formado entre Fe(II) e o ferricianeto também é grande, mas a construção da curva analítica não é muito simples. Além disso, o descarte dos subprodutos é muito mais difícil. O complexo formado neste caso é de cor azul, mas o excesso do reagente inicial deixa a solução esverdeada, o que impossibilita, por exemplo, uma determinação quantitativa direta, por comparação visual de intensidade de cores $^{10}$.

Verifica-se que na obtenção da curva analítica há um procedimento onde se usam 8 balões volumétricos. Também neste caso podem ser feitas adaptações para a se obter os resultados, por exemplo, utilizando-se adições de volumes conhecidos em tubos de ensaio. Em se tratando de alunos iniciantes e em disciplinas de Química Geral, não é necessário muito rigor, como já foi dito anteriormente. Basta que o Professor comente estes aspectos com os alunos.

No experimento IV, o rendimento quântico para a reação proposta gira em torno de 1,2 na região do ultravioleta e a partir de 400 $\mathrm{nm}$ começa a diminuir, sendo muito próximo de 1 entre 400 e 510 $\mathrm{nm}^{22,23}$. Para radiações de comprimento de onda maior, o rendimento quântico cai bastante, assim como a absortividade do complexo. 
Estes fatos serão importantes quando o Professor estiver discutindo a cinética fotoquímica em seus aspectos qualitativos (usando papel celofane). No entanto, os alunos não devem ter conhecimento destes fatos antes da realização do experimento IV. Isto é uma "descoberta" que eles devem realizar à luz dos resultados experimentais e com a intervenção adequada do Professor. Neste caso específico, "descobrir" é mais um ato de correlação entre os resultados obtidos e não de "descobrir" as leis que regem a indução de uma reação fotoquímica.

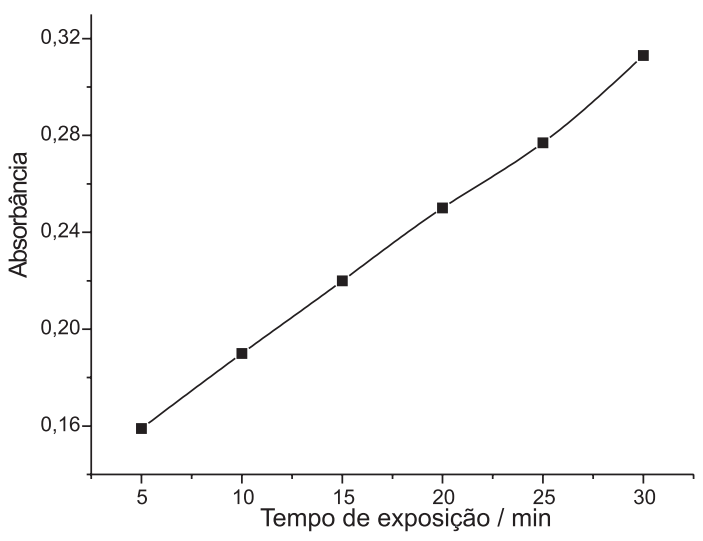

Figura 1. Resultados de absorbância, em $510 \mathrm{~nm}$, de soluções de tris(oxalato) ferrato(III) de potássio, tri-hidratado em função do tempo de exposição à luz difusa

O gráfico da Figura 1 foi obtido utilizando-se tubos de ensaio de $10 \mathrm{~mm}$ de diâmetro interno e paredes de espessura de $1 \mathrm{~mm}$, sob as seguintes condições de iluminação: luz difusa de 5 lâmpadas de $40 \mathrm{~W}$ fluorescentes brancas, iluminando $12 \mathrm{~m}^{2}$ de área em um ambiente de pé direito igual a 3,5 metros. A luminosidade tem papel decisivo nas condições experimentais a serem adotadas, principalmente aquelas relativas ao tempo de exposição. O que se recomenda é que o Professor teste estas condições e faça as adaptações conforme as necessidades. Experimentos realizados no período noturno podem requerer um tempo maior de exposição.

O Professor pode adequar também a área de exposição, usando tubos de diferentes diâmetros, alterando os volumes de solução, alterando o caminho óptico ou mesmo a concentração da solução inicial. Seria impossível detalhar, neste trabalho, todas as condições experimentais possíveis mas, com um pouco de criatividade, o Professor é capaz de superar estes pequenos obstáculos e criar outras opções experimentais.

O Professor deve estar atento às manipulações em ausência de luz. Verificamos que com as lâmpadas apagadas, a luz que entrava no laboratório não era suficiente para interferir nos resultados, quando estas manipulações demoravam em torno de um ou dois minutos.

A Figura 2 apresenta as curvas de absorção de luz visível dos diversos papéis celofane. Sua análise revelará aspectos curiosos para os alunos. O papel de cor amarela, por exemplo, absorve parte da luz na região entre 400 e $500 \mathrm{~nm}$, onde a reação apresenta maior rendimento quântico, mas não consegue cortar toda a luz nesta faixa. Embora o verde transmita numa região de alto rendimento quântico da reação, entre 480 e $515 \mathrm{~nm}$, a sua absorção de radiação em outras faixas é acentuada. Assim, uma comparação entre a extensão da reação para estes dois filtros, poderia indicar, sem o prévio conhecimento das curvas de absorção destes filtros, que o verde daria maior quantidade de produtos para um mesmo tempo de irradiação, o que não foi observado (veja Tabela 1).

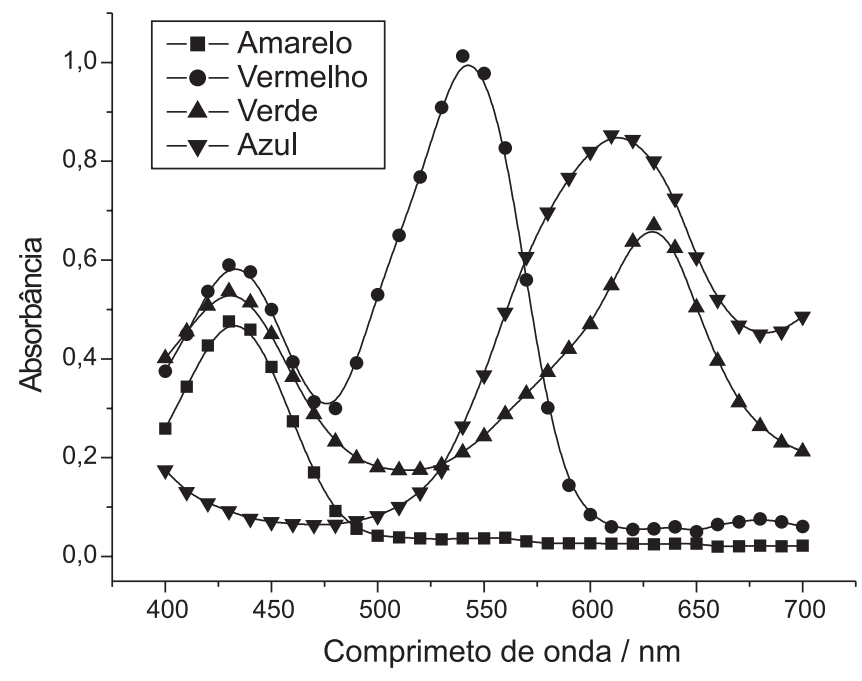

Figura 2. Espectro de absorção na região do visível para os diversos papéis celofane

Tabela 1 - Resultados de extensão da reação de oxidação e redução induzida por luz de soluções tris(oxalato) ferrato(III) de potássio, tri-hidratado protegidas por filtros ópticos de papel celofane, expostas à luz difusa por $90 \mathrm{~min}$

\begin{tabular}{|c|c|c|}
\hline Papel & Absorbâncias & {$[\mathrm{Fe}(\mathrm{II})]$ formado/ $\mathrm{mol} \mathrm{dm}^{-3}$} \\
\hline Vermelho & 0,134 & $1,70 \times 10^{-5}$ \\
\hline Verde & 0,161 & $2,04 \times 10^{-5}$ \\
\hline Amarelo & 0,201 & $2,56 \times 10^{-5}$ \\
\hline Azul & 0,687 & $8,75 \times 10^{-5}$ \\
\hline Sem Papel & 1,520 & $1,93 \times 10^{-4}$ \\
\hline
\end{tabular}

Ao se analisar as curvas da Figura 2, vê-se que, na região de rendimento quântico alto, os dois filtros (verde e amarelo) absorvem a radiação em quantidades próximas, mas o amarelo absorve menos. Em todas as regiões, o amarelo absorve menos que o verde, o que qualitativamente pode ser inferido pela observação direta e pela comparação da luz que passa através dos dois papéis, sendo o amarelo muito mais transparente. Além disso, o amarelo praticamente não absorve nada acima de $500 \mathrm{~nm}$, englobando, assim, uma pequena região onde o complexo absorve bastante e o rendimento quântico é alto.

Os filtros azul e vermelho estão nos extremos. O azul absorve bastante a radiação acima de $530 \mathrm{~nm}$, onde o complexo absorve pouco e o rendimento quântico é baixo, e o vermelho absorve bastante em toda a faixa de 400 até $600 \mathrm{~nm}$. Onde o vermelho transmite, o rendimento quântico é baixo e a absorção de luz pelo complexo em solução é praticamente nula. Os resultados da Tabela 1 confirmam esta interpretação, já que se combinam positivamente os fatores de aumento de quantidade de luz que passa pelo filtro, a absortividade do complexo que está sofrendo a reação e o rendimento quântico desta reação. Muitas outras observações e comparações poderiam ser aqui discutidas, no entanto, devido ao conhecimento prévio que os Professores têm deste assunto e aos propósitos do trabalho, cremos que isto é o suficiente.

Finalmente, a periculosidade e insalubridade intrínsecas ao experimento são mínimas e os rejeitos são de fácil descarte. As soluções ácidas utilizadas não têm altas concentrações e, portanto não exigem cuidados especiais. Recomenda-se, no entanto, o uso dos equipamentos de proteção. Quanto ao metanol utilizado no experi- 
mento I, ele deve ser manuseado e utilizado dentro da capela. O seu perigo maior reside na possibilidade de inalação ou ingestão podendo, aí, ter consequiências piores. O seu descarte deve ser feito em frasco separado para posterior destruição.

\section{REFERÊNCIAS}

1. DeMeo, S.; J. Chem. Educ. 2001, 78, 201.

2. Moss, D. B.; Cornely, K.; J. Chem. Educ. 2001, 78, 1260.

3. Mars, P. S.; J. Chem. Educ. 2001, 2, 78, 527

4. Hass, M. A.; J. Chem. Educ. 2000, 77, 1035.

5. Curtright, R. D.; Emry, R.; Markwell, J.; J. Chem. Educ. 1999, 76, 249.

6. Hatchard, C.G.; Parker, C.A.; Proc. Roy. Soc. (London) 1956, A235, 518.

7. Dallinger, R. F.; J. Chem. Educ. 1995, 72, 936.

8. Young, C. G.; J. Chem. Educ.; 1985, 62, 445.

9. Olmsted III, J.; J. Chem. Educ. 1984, 61, 1098

10. Baker, A. D.; Casadevall, A.; Gafney, H. D.; Gellender, M.; J. Chem. Educ. 1980, 57, 314.

11. Aravamudan, G.; Gopalakrishnan, J.; Udupa, M. R; J. Chem. Educ. 1974 $51,129$.

12. Brooks, D. W.; J. Chem. Educ. 1973, 50, 218.
13. Basset, J.; Denney, R. C.; Jeffery, G. H.; Mendham, J. (revisores); VogelAnálise Inorgânica Quantitativa, $4^{\mathrm{a}}$ ed., Editora Guanabara: Rio de Janeiro, 1978 , p. 262.

14. Baccan, N.; de Andrade, J. C.; Godinho,O. E. S.; Barone, J. S.; Química Analítica Quantitativa Elementar, 2a ed., Editora Edgard Blücher: São Paulo, 1998, p. 193.

15. Baccan, N.; de Andrade, J. C.; Godinho, O. E. S.; Barone, J. S.; Química Analítica Quantitativa Elementar, $2^{\mathrm{a}}$ ed., Editora Edgard Blücher: São Paulo, 1998, p. 3.

16. Skoog, D. A.; West, D. M.; Holler, F. J.; Fundamentals of Analytical Chemistry, $7^{\text {th }}$ ed., Harcourt College Publishers: Orlando, 1996, p. 21.

17. Cantarela, H.; Quaggio, J. A.; de Andrade, J. C. Em Análise Química para Avaliação da Fertilidade de Solos Tropicais; Instituto Agronômico: Campinas, 2001, p. 142.

18. Ref. 13, p. 552.

19. Ref. 16, p. 497.

20. De Paoli, M. A.; Jorge, R. A. C; Quim. Nova 1980, 1, 34.

21. Slowinski, E. J.; Masterton, W. L.; Wolsey, W. C.; Chemical Principles in the Laboratory, W.B. Saunders Company: Phyladelphia, 1973, p. 143.

22. Murov, S. L.; Carmichael, I.; Hug, G.L.; Handbook of Photochemistry, $2^{\text {nd }}$ ed., Marcel Deker, Inc.: New York, 1999, p. 301.

23. Calvert, J. G.; Pitts Jr., J. N.; Photochemistry, John Wiley and Sons, Inc.: New York, 1999, p. 784. 